
\title{
3 Research Square \\ The influence of solar and geomagnetic activity on human heart rhythms
}

\author{
Abdullah Alabdulgader \\ Rollin McCraty \\ Michael Atkinson \\ York Dobyns \\ Alfonsas Vainoras \\ Minvydas Ragulskis \\ Viktor Stolc
}

\section{Video Abstract}

Keywords: heart rate variability, solar, geomagnetic, magnetic, autonomic nervous system, magnetic field, activity, ANS, circadian, solar wind, solar radio flux, cosmic rays, Schumann resonance, biological stress response, parasympathetic activity, sunspot, environmental variable, Tchijevsky, HeartMath Institute, Scientific Reports

Posted Date: September 20th, 2019

DOI: https://doi.org/10.21203/rs.2.14969/v1

License: (c) (1) This work is licensed under a Creative Commons Attribution 4.0 International License. Read Full License 


\section{Abstract}

As we go about our daily lives, we aren't generally aware of the forces generated by solar activity or the earth's magnetic field. While these planetary changes are well documented, precisely how they affect human beings is less clear. To answer this question, researchers have turned to the autonomic nervous system - the subconscious control system that regulates bodily functions such as breathing and digestion. Their findings suggest that our nervous systems are well attuned to the energetic fluctuations that ripple through our solar system. The work builds on observations made by the famed astronomer Alexander Chizhevsky during World War I. He noted that battles intensify during peak solar flare periods and that major human events and behaviors closely follow the cycle of the sun - which led to the hypothesis that some unknown solar forces affect human health and behavior, providing a provocative link between events occurring in our solar system and life on Earth. To test this hypothesis scientifically, the team looked at how the human nervous system responds to changes in solar and cosmic radiation as well as in the Earth's magnetic field. They accomplished this by focusing on heart rate variability - an indicator of autonomic nervous system function. This variability was tracked in sixteen women, who wore heart rate monitors for 72 hours per week for 5 months. The data were then compared to changes in cosmic rays as well as geomagnetic and solar activity occurring over the same period. The team found that heart rate variability significantly correlated to variations in three key variables: cosmic rays, solar activity and Schumann resonances. Strikingly, the participants' heart rate variability rose in response to increases in these variables - and the response was quite rapid. These positive correlations suggest that human physiology reacts favorably to these forces, supporting Chizhevsky's hypothesis that environmental factors can act as energy sources that affect health, mood and behavior. Although the full importance of these relationships isn't currently known, the findings suggest that cosmic and solar energy don't just change Earth's magnetic field - they also affect human physiology. The work also poses the intriguing suggestion that some aspects of these energies might subconsciously connect human beings across the world. 